\title{
Acceleration of Fetal Lung Maturation by Aminophyllin in Pregnant Rabbits
}

\author{
EDWARD H. KAROTKIN, MASAMITSU KIDO, WILLIAM J. CASHORE, RALPH A. REDDING, \\ WILLIAM J. DOUGLAS, LEO STERN, AND WILLIAM OH ${ }^{(16)}$ \\ Department of Pediatrics, Women and Infants Hospital of Rhode Island, Department of Medicine, Pawtucket \\ Memorial Hospital, Brown University Program in Medicine, Providence, Rhode Island, USA
}

\section{Extract}

To test the hypothesis that fetal lung maturation can be accelerated by one of the xanthine derivatives, aminophyllin was given to 40 pregnant rabbits beginning on the 20 th gestational day for a period of 7-10 days. The fetuses were delivered by cesarean section and fetal lung maturity was assessed by determining the biochemical, functional, and ultrastructural characteristics of aminophyllin-treated $v s$. control animals. The phospholipid content of the lung tissue homogenate from the aminophyllin-treated group was significantly higher than in the control subjects (saline injected) at 28 days of gestation $(421 \pm 9 v s .368 \pm 12 \mu \mathrm{g} / \mathrm{mg}$ wet wt, mean $\pm \mathrm{SEM})$ and at 29 days of gestation $(531 \pm 10 \mathrm{vs} .475 \pm 20)$. The alveolar wash phospholipid content of the aminophyllin-treated group was higher at 30 days $(167 \pm 9 \mu \mathrm{g} / \mathrm{mg}$ dry wt, mean $\pm \mathrm{SEM}$ vs. $117 \pm 17$ ). The lung compliance derived from pressure volume curves was also significantly higher in the aminophyllin-treated group when compared with controls at 27 days of gestation $(0.023 \pm$ $0.0005 \mathrm{ml} / \mathrm{cm} \mathrm{H}_{2} \mathrm{O}$, mean $\pm \mathrm{SEM}$ vs $\left.0.010 \pm 0.0002\right)$ and at 28 days of gestation $(0.048 \pm 0.0003$ vs $0.035 \pm 0.0006)$. There was no significant difference in the number of lamellar bodies in the type II cells between the aminophyllin-treated and the control groups. The data show that aminophyllin has accelerating effects on fetal lung maturation in rabbits when the drug is given to pregnant rabbits during the last 7-10 days of gestation.

\section{Speculation}

Our data do not permit extrapolation into the clinical application of utilizing xanthine derivatives for the enhancement of fetal lung maturation. However, they provide evidence that there may be several pharmacologic agents that might enhance fetal lung maturation by various mechanisms. These data may also provide impetus for some centers to review the statistical correlation of respiratory distress syndrome in infants born to mothers who have received xanthine derivatives during the latter part of pregnancy for the treatment of such conditions as bronchial asthma. If the latter clinical evidence is a positive one, it may be justified to initiate a clinical trial to evaluate the effect of xanthine derivative treatment of the mother for the purpose of preventing respiratory distress syndrome in the newborn infant.

It has been shown previously that maternal administration of steroids can induce fetal lung maturation in a number of animal species (3, 5-7, 9, 14). Studies by Liggins and Howie (8) have demonstrated an acceleration of fetal lung maturation in humans as indicated by a reduction in the incidence of respiratory distress syndrome when a corticosteroid (betamethasone) was administered parenterally to the mothers $48-72 \mathrm{hr}$ before delivery. The precise mechanism by which the acceleration of fetal maturation occurs is not yet certain. Lung surfactant synthesis in the type II cell, storage in lamellar bodies within this cell, and ultimate release into the alveolus are probably governed by a number of interrelated factors. However, recent evidence suggests that adenosine 3',5'-monophosphate (cyclic AMP) may be one of the important intermediate compounds regulating the synthesis of surfactant $(2$, 13). It is also known that drugs such as xanthine derivatives may increase the level of cyclic AMP by the inhibition of phosphodiesterase, the enzyme responsible for the normal breakdown of cyclic AMP. This study was undertaken to evaluate the effect of a xanthine derivative (aminophyllin) on the process of lung maturation in the rabbit fetus when administered to pregnant rabbits 7-10 days before term, with assessment of the rate of lung maturation by biochemical, functional, and ultrastructural measurements.

\section{MATERIALS AND METHODS}

Forty time-dated (time of mounting used as time zero) pregnant new Zealand rabbit does were treated at 20 days of gestation with twice daily intramuscular injections of either normal saline (0.5 ml/dose-control group) or aminophyllin (10 mg/ $\mathrm{kg}$ body wt) until the time of delivery. The duration of treatment ranged from 7-10 days depending on the gestational age at the time of delivery. Thus, fetuses delivered at 27 days of gestation would have received 7 days of either normal saline or aminophyllin treatment. Those delivered at 28 days would have received 8 days, etc. The does in both treated and control groups were fed ad libitum with water and Purina chow. During the treatment period, no obvious differences were observed in activities and behaviors between the saline- and aminophyllin-treated groups. The mean maternal weight gain during the treatment periods (initiation of saline or aminophyllin treatment to the time of delivery) was also comparable between the two groups (400 (saline) vs. $450 \mathrm{~g}$ (aminophyllin)).

The fetuses were delivered by hysterotomy under intravenous Nembutal anesthesia at 27, 28, 29, and 30 days of gestation. There was a $10-15 \%$ abortion rate in the treatment group. The amount of fetal wastage per litter was the same for both control and treatment groups. The fetuses were permitted to breathe room air for 15-20 min before each fetus was weighed and tracheostomy performed on one-half of the litter. There was no difference in the amount of gasping during the 15-20-min period between the treatment and control groups. After the placement of a tracheal cannula, the head and trunk below the diaphragm were removed, leaving the lungs intact within the thoracic cavity. The lung preparation was suspended in a sealed glass chamber and by using the microspirometer technique, 9-19 successive pressure volume curves were performed until a stable tracing was obtained (10). The compliance for each curve $\left(\mathrm{ml} / \mathrm{cm} \mathrm{H}_{2} \mathrm{O}\right)$ was calculated from a stable curve using opening pressure as the reference point for the determination of tidal volume. If a lung failed to expand, as was frequently the case in the 27 -day control group, zero compliance was assigned to that lung. 
After the completion of the pressure volume curves, alveolar wash was obtained from these lungs by lavaging the tracheobroncheal tree through the catheter $10-12$ times with a total volume of 1-2 $\mathrm{ml}$ normal saline. The lungs were dried in a desiccator at $75^{\circ}$ for at least $24 \mathrm{hr}$, and a dry lung weight was obtained for unit expression of phospholipid content. The alveolar washings were combined from each pair of fetal lungs, and differentially centrifuged as previously described by Redding et al. $(10,11)$ to obtain the surfactant pellet. The pellet was dissolved in a $2: 1$ chloroformmethanol mixture and subsequently analyzed for phospholipid content according to the method of Chen et al. (4).

The lung tissue from the other half of the litter (three to four fetuses) was removed in toto, weighed, and homogenized in a Teflon grinder. Neutral phospholipids were isolated from other lipids using DEAE-cellulose acetate column chromatography (12). The lung phospholipid content was expressed per unit wet weight.

The lungs from three to four fetuses belonging to the 28th to the 30 th day of gestation of each group were prepared for electron microscopy using the conventional techniques. Twenty-five type II cells from each lung were examined and the average number of the lamellar bodies were determined by one of us (W.J.D.) who was unaware of the group source of the lung tissue.

The comparison of the data between control and aminophyllin treated groups was made by student $t$-test, using the means of litters.

\section{RESULTS}

As shown on Table 1, there was no significant difference in the body weight, fresh and dry lung weights between the controls and aminophyllin-treated groups. Table 2 shows that the phospholipid content of lung tissue and alveolar wash of both control and aminophyllin-treated groups rose as would be expected with advancing gestational age. Furthermore, the aminophyllin-treated pups had significantly greater amounts of phospholipid in the lung tissue at 28 and 29 days and in the alveolar wash at 30 days. Table 3 shows that the lung compliance of both and control and aminophyllin-treated groups increased significantly with increasing gestational age. Furthermore, the lung compliance of the aminophyllin-treated pups was significantly greater than that of the controls at 27 and 28 days of gestation.

There was no significant difference in the number of lamellar bodies in the aminophyllin-treated pups at all gestational ages when compared with controls (Table 4).

\section{DISCUSSION}

Previous reports have shown that the phospholipid content of the alveolar fluid in lung tissue correlates well with functional maturation of the lung, and is a reflection of the surfactant lipids at the alveolar interface. In this study, we have shown that there is progressive increment in the phospholipid content of lung tissue and alveolar wash with increasing maturation. With maternal treatment of aminophyllin, a significantly higher phospholipid content in the lung tissue at 28 and 29 days of gestation and in the lung wash at 30 days of gestation was observed, indicating an acceleration of the rate of lung maturation in the fetus with increased synthesis, storage, and release of surfactant in the alveolar cell.

The lung compliance data provides additional support to the biochemical observations. The aminophyllin-treated group shows greater lung compliance, which would reflect a more elastic lung as a result of a greater amount of surfactant present at the alveolar interface. It is important to note that the improvement in lung compliance in the preterm treatment group is not better than that found in term animals, suggesting that higher levels of surfactant will not improve the mechanical property of the lung beyond its normal functional ability at term.

Other studies have suggested that the lamellar bodies are the site of surfactant production and release and, therefore, their appear-

Table 1. Body weights, fresh and dry lung weight of control (saline-treated) and aminophyllin-treated rabbit fetuses ${ }^{1}$

\begin{tabular}{|c|c|c|c|c|c|c|}
\hline \multirow{2}{*}{$\begin{array}{c}\text { Gestation, } \\
\text { days }\end{array}$} & \multicolumn{2}{|c|}{ Body wt, g } & \multicolumn{2}{|c|}{ Fresh lung wt, g } & \multicolumn{2}{|c|}{ Dry lung wt, mg } \\
\hline & Controls & Aminophyllin & Controls & Aminophyllin & Controls & Aminophyllin \\
\hline 28 & $\begin{array}{c}33.2 \pm 1.8 \\
(39 / 6)\end{array}$ & $\begin{array}{c}36.2 \pm 1.2 \\
(36 / 5)\end{array}$ & $\begin{array}{c}0.99 \pm 0.08 \\
(13 / 6)\end{array}$ & $\begin{array}{c}1.2 \pm 0.04 \\
(17 / 5)\end{array}$ & $\begin{array}{l}121 \pm 5 \\
(26 / 6)\end{array}$ & $\begin{array}{r}114 \pm 4 \\
(19 / 5)\end{array}$ \\
\hline 30 & $\begin{array}{c}43.0 \pm 2.2 \\
(49 / 7)\end{array}$ & $\begin{array}{c}41.6 \pm 3.6 \\
(24 / 4)\end{array}$ & $\begin{array}{c}1.04 \pm 0.07 \\
(25 / 7)\end{array}$ & $\begin{array}{c}0.96 \pm 0.05 \\
(13 / 4)\end{array}$ & $\begin{array}{c}131 \pm 3 \\
(24 / 7)\end{array}$ & $\begin{array}{c}110 \pm 10 \\
(11 / 4)\end{array}$ \\
\hline
\end{tabular}

${ }^{1}$ Mean \pm SEM (of all fetuses studied in each gestation). Values within parentheses indicate the number of fetuses per number of litters for each gestation group.

Table 2. Lung tissue and alveolar wash phospholipid contents in aminophyllin-treated rabbit fetus ${ }^{1}$

\begin{tabular}{|c|c|c|c|c|}
\hline \multirow{2}{*}{$\begin{array}{l}\text { Gestation, } \\
\text { days }\end{array}$} & \multicolumn{2}{|c|}{ Tissue phospholipid content, $\mu \mathrm{g} / \mathrm{mg}$ wet lung } & \multicolumn{2}{|c|}{$\begin{array}{l}\text { Alveolar wash phospholipid } \\
\text { content, } \mu \mathrm{g} / \mathrm{mg} \text { dry lung }\end{array}$} \\
\hline & Control & Aminophyllin & Control & Aminophyllin \\
\hline 27 & $358 \pm 9(13 / 4)$ & $343 \pm 10(11 / 4)$ & $7 \pm 2(10 / 4)$ & $8 \pm 1(7 / 4)$ \\
\hline 28 & $368 \pm 12(10 / 6)$ & $421 \pm 9^{2,3}(17 / 5)$ & $54 \pm 8^{2}(18 / 6)$ & $43 \pm 4^{2}(15 / 5)$ \\
\hline 29 & $475 \pm 20^{2}(16 / 4)$ & $531 \pm 10^{2,3}(24 / 6)$ & $76 \pm 4^{2}(13 / 4)$ & $91 \pm 7^{2}(22 / 6)$ \\
\hline
\end{tabular}

${ }^{1}$ Values are means \pm SEM. Values within parentheses indicate number of fetuses per number of litters studied.

${ }^{2} P<0.05$ when compared with values for previous day of same group.

${ }^{3} P<0.05$ when compared with controls of identical gestation. 
Table 3. Lung compliance in aminophyllin-treated rabbit fetus ${ }^{1}$

\begin{tabular}{ccc}
\hline & \multicolumn{2}{c}{ Lung compliance, $\mathrm{ml} / \mathrm{cm} \mathrm{H}_{2} \mathrm{O}$} \\
$\begin{array}{c}\text { Gestation, } \\
\text { days }\end{array}$ & \multicolumn{1}{c}{ Control } & Aminophyllin \\
\hline 27 & $0.010 \pm 0.0002(20 / 4)$ & $0.023 \pm 0.0005(16 / 4)^{2}$ \\
28 & $0.035 \pm 0.0006(24 / 6)^{3}$ & $0.048 \pm 0.0003(32 / 5)^{2,3}$ \\
29 & $0.059 \pm 0.0004(18 / 4)^{3}$ & $0.058 \pm 0.0007(19 / 6)^{3}$ \\
30 & $0.083 \pm 0.001(11 / 7)^{3}$ & $0.074 \pm 0.0002(13 / 4)^{3}$ \\
\end{tabular}

${ }^{1}$ Values are mean \pm SEM. Values within parentheses indicate number of fetuses per number of litters studied; three to four stable pressure volume curves.

${ }^{2} P<0.05$ when the values were compared between groups of the same gestation.

${ }^{3} P<0.05$ when the values were compared with those of the previous gestational day of the same group.

ance should correlate with the biochemical and functional status of the lung $(1,15)$. We were unable to show an absolute increase in the number of lamellar bodies in the aminophyllin-treated group. It is possible that aminophyllin, acting as a phosphodiesterase inhibitor, would increase the quantity of cyclic AMP available in the lamellar body, which in turn would produce more surfactant. If this is true, it may not be necessary for the increment in functional activity to be accompanied by an increase in the number of lamellar bodies in the type II cell.

A recent study by Barrett et al. (2) demonstrated that pregnant rabbits treated with aminophyllin showed an increase in cyclic AMP in the lung tissue of the fetus. This would further support the theory that the mechanism of the stimulatory effect of aminophyllin on fetal lung maturation is mediated through increased levels of cyclic AMP in the lung tissue secondary to the inhibition of phosphodiesterase.

\section{SUMMARY}

Maternal administration of aminophyllin produced a biochemical and functional enhancement of the rabbit fetal pulmonary maturation. Greater amounts of phospholipid were found in the lung tissue homogenate of fetuses at 28 and 29 days of gestation. and the phospholipid content of the alveolar wash was also higher at 30 days in the aminophyllin-treated fetuses. Lung compliance was higher in the experimental animals at 27 and 28 days of gestation. No difference was observed in the number of lamellar bodies in the type II cell between the aminophyllin-treated and the control group. It was hypothesized that aminophyllin enhanced fetal lung maturation by inhibiting the phosphodiesterase activity (enzyme responsible for the degradation of cyclic AMP), hence resulting in a higher concentration of cyclic AMP, a known essential intermediary substance for the synthesis of surfactant in the lung.
Table 4. Lamellar bodies (number per type II cell) in lung of aminophyllin-treated pups ${ }^{1}$

\begin{tabular}{ccc}
\hline $\begin{array}{c}\text { Gestation, } \\
\text { days }\end{array}$ & Control & Aminophyllin \\
\hline 28 & $3.7 \pm 0.4$ & $4.1 \pm 0.3$ \\
& $(3)$ & $(3)$ \\
29 & $6.5 \pm 0.5$ & $6.7 \pm 0.4$ \\
& $(3)$ & $(3)$ \\
30 & $5.3 \pm 0.3$ & $4.5 \pm 0.4$ \\
& $(4)$ & $(3)$ \\
\hline
\end{tabular}

${ }^{1}$ Values are mean \pm SEM. Values within parentheses indicate number of fetuses (from different litters) studied. The value from each fetus is the average of lamellar bodies counted in 25 type II cells.

\section{REFERENCES AND NOTES}

1. Balis, J. V., and Conen, P. E.: The role of alveolar inclusion bodies in the developing lung. Lab Invest., 13: 1215 (1964).

2. Barrett, C. T., Sevanian, A., and Kaplan, S. A.: Cyclic AMP (cAMP) and surfactant production: New means for enhancing lung maturation in the fetus [Abstract]. Pediat. Res., 9: 394 (1975).

3. Carson, S., Taeusch, H. W., Jr., and Avery, M. E.: The effects of cortisol injection on lung growth in fetal rabbits. J. Appl. Physiol., 34: 660 (1973)

4. Chen, P. S., Toribara, T. Y., and Warner, H.: Microdetermination of phosphorous. Anal. Chem., 28: 1756 (1956).

5. deLemos, R. A., Shermeta, D. W., Knelson, J. H., Kotas, R., and Avery, M. E.: Acceleration of appearance of pulmonary surfactant in the fetal lamb by administration of corticosteroids. Amer. Rev. Resp. Dis., 102: 459 (1970).

6. Farrell, P. M. and Zachman, R. D. Enhancement of lecithin synthesis and phosphorylcholine glyceride transferase activity in the fetal rabbit lung after corticosteroid administration [Abstract]. Pediat. Res., 6: 377 (1972).

7. Liggins, G. C.: Premature delivery of foetal lambs infused with glucocorticoids. J. Endocrinol., 45: 515 (1969)

8. Liggins, G. C., and Howie, R. N.: A controlled trial of antepartum glucocorticoid treatment for prevention of the respiratory distress syndrome in premature infants. Pediatrics, 50: 515 (1972).

9. Motoyama, E. K. Orzalesi, M. M., Kikkawa, Y., Kaibard, M., Wu. B., Zigas, C. J., and Cook, C. D.: Effect of cortisol on the maturation of fetal rabbit lungs. Pediatrics. 48: 547 (1971)

10. Redding, R. A., Arai, T., Douglas, W., Tsurutani, H., and Overs, J.: Early changes in the lungs of rats exposed to $70 \%$ oxygen. J. Appl. Physiol. 38: 136 (1975)

11. Redding, R. A., Douglas, W. H. J., and Stein, M.: Thyroid hormone influence upon lung surfactant production. Science, 17: 194 (1972).

12. Skipski, V. P., Peterson, R. F., Saunders, J., and Barclay, M.: Thin-layer chromatography of phospholipids using silica gel without calcium sulfate binder. J. Lipid. Res, 4: 227 (1963)

13. Stahlman, M. T. Gray, M. E., Leiu, S, and Chytil, R. The role of cyclic AMP in lamellar body synthesis and secretion [Abstract]. Pediat. Res., 8: 470 (1974).

14. Taeusch, H. W., Jr., Heitner, M., and Avery, M. E.: Accelerated lung maturation and increased survival in premature rabbits treated with hydrocortisone. Amer. Rev, Resp. Dis, 105: 972 (1972)

15. Wang, N. S., Kotas, R. V., and Avery, M. E.: Accelerated appearance of osmiophilic bodies in fetal lungs following steroid injection. J. Appl. Physiol., 30: 362 (1971).

16. Requests for reprints should be addressed to: W. Oh, M.D., Department of Pediatrics, Women and Infants Hospital of Rhode Island, 50 Maude St., Providence, R. I. 02908 (USA).

17. Accepted for publication February 17, 1976. 